\title{
Validity of the dietary reference intakes for determining energy requirements in older adults
}

\author{
Didace Ndahimana', Na-Young Go ${ }^{1}$, Kazuko Ishikawa-Takata ${ }^{2}$, Jonghoon Park ${ }^{3}$ and Eun-Kyung Kim ${ }^{15}$ \\ 'Department of Food and Nutrition, Gangneung-Wonju National University, 7 Jukheon-gil, Gangneung 25457, Korea \\ ${ }^{2}$ Department of Nutrition and Metabolism, National Institutes of Biomedical Innovation, Health and Nutrition, Tokyo 162-8636, Japan \\ ${ }^{3}$ Department of Physical Education, Korea University, 145 Anam-Ro, Seongbuk-Gu, Seoul 02841, Korea
}

BACKGROUND/OBJECTIVES: The objectives of this study were to evaluate the accuracy of the Dietary Reference Intakes (DRI) for estimating the energy requirements of older adults, and to develop and validate new equations for predicting the energy requirements of this population group.

MATERIALS/METHODS: The study subjects were 25 men and 23 women with a mean age of $72.2 \pm 3.9$ years and $70.0 \pm 3.3$ years, and mean BMI of $24.0 \pm 2.1$ and $23.9 \pm 2.7$, respectively. The total energy expenditure (TEE) was measured by using the doubly labeled water (DLW) method, and used to validate the DRI predictive equations for estimated energy requirements (EER) and to develop new EER predictive equations. These developed equations were cross-validated by using the leave-one-out technique.

RESULTS: In men, the DRI equation had a $-7.2 \%$ bias and accurately predicted the EER (meaning EER values within $\pm 10 \%$ of the measured TEE) for $64 \%$ of the subjects, whereas our developed equation had a bias of $-0.1 \%$ and an accuracy rate of $84 \%$. In women, the bias was $-6.6 \%$ for the DRI equation and $0.2 \%$ for our developed equation, and the accuracy rate was $74 \%$ and $83 \%$, respectively. The predicted EER was strongly correlated with the measured TEE, for both the DRI equations and our developed equations (Pearson's $r=0.915$ and 0.908 , respectively).

CONCLUSIONS: The DRI equations provided an acceptable prediction of EER in older adults and these study results therefore support the use of these equations in this population group. Our developed equations had a better predictive accuracy than the DRI equations, but more studies need to be performed to assess the performance of these new equations when applied to an independent sample of older adults.

Nutrition Research and Practice 2019;13(3):256-262; https://doi.org/10.4162/nrp.2019.13.3.256; plSSN 1976-1457 elSSN 2005-6168

Keywords: Nutritional requirements, energy metabolism, elderly

\section{INTRODUCTION}

Recently, the number of older adults has been increasing across the world [1] and this change has an impact on global and national public health systems [2]. Aging is among the risk factors for developing non-communicable chronic diseases (NCCDs) [3,4]. In older adults, regular physical activity is associated with a reduced mortality [5,6], a decreased risk for NCCDs such as type 2 diabetes, cardiovascular disease and cancer [7-9] and a decreased prevalence of cognitive impairment[10]. However, studies have shown that aging is accompanied by a decline in physical activity [11,12], contributing to reduced energy requirements in older adults [13]. In addition to this low level of physical activity, aging results in metabolic changes which influence the energy requirements of older adults. Compared to younger people, older adults have a lower resting energy expenditure (REE), which is related to the loss of fat-free mass
(FFM) accompanying the aging process $[14,15]$.

This context raises the importance of accurate assessment of older adults' energy requirements. This can be achieved by measuring the total energy expenditure (TEE), which is equal to estimated energy requirements (EER) for adults who no longer have the need for tissue growth and maturation and who are in energy equilibrium [16]. The most accurate method for measuring TEE is the doubly labeled water (DLW) method, which is based on the use of hydrogen and oxygen stable isotopes [17]. The method is used as the gold standard in the development and validation of other methods of energy expenditure assessment. The limitation of the DLW method remains its high cost, which limits its use in studies and has reduced the number of subjects in most studies.

In its 2002 report, the Institute of Medicine of the National Academies published various equations for estimating the energy requirements for the different population groups, based

\footnotetext{
This research was supported by a grant from the National Research Foundation of Korea (Project number: 2016R1D1A1B03935571).

${ }^{\S}$ Corresponding Author: Eun-Kyung Kim, Tel. 82-33-640-2336, Fax. 82-33-640-2330, E-mail. ekkim@gwnu.ac.kr

Received: April 17, 2019, Revised: May 10, 2019, Accepted: May 23, 2019

This is an Open Access article distributed under the terms of the Creative Commons Attribution Non-Commercial License (http://creativecommons.org/licenses/by-nc/3.0/) which permits unrestricted non-commercial use, distribution, and reproduction in any medium, provided the original work is properly cited.
} 
on the TEE results of different DLW studies conducted in Americans and Canadians in previous years [16]. During these predictive equations development, older adults were not considered separately as a group. However, various studies have indicated that aging is associated with changes in energy metabolism [18,19], which could affect the accuracy of these equations when applied to older adults. The objectives of this study were to evaluate the accuracy of the Dietary Reference Intakes (DRI) for estimating the energy requirements of older adults, and to develop new equations for predicting the energy requirements of this population group on a trial basis.

\section{SUBJECTS AND METHODS}

\section{Subjects}

The study subjects were forty-eight older adult subjects ( 25 men and 23 women), living in Gangneung city, Gangwon Province, South Korea. The inclusion criteria were: (1) Being aged 65 years or older, (2) having a normal body weight (18.5 $\leq \mathrm{BMl}<30$ ), (3) not being on a diet plan for weight change, (4) not regularly engaging in hard activities such as athletes, (5) not having a disease or taking medicines that have an impact on energy or water metabolism, and (6) staying in the study province for at least two weeks before and during the study. The study was approved by the Institutional Review Board (IRB) of Gangneung-Wonju National University (approval number GWNUIRB-2016-26-1). In addition, informed consent was received from every subject before enrolling in the study.

\section{Anthropometry and body composition measurements}

The subjects' body weight and height were measured by using a stadiometer, with the subjects wearing the lightest clothes possible and without shoes. The BMI was calculated as the subject's weight $(\mathrm{kg})$ divided by the height squared $\left(\mathrm{m}^{2}\right)$. Body composition was assessed through the bioelectrical impedance analysis (BIA), using Inbody 720 Body Composition Analyzer (Biospace, Korea).

\section{REE}

In the majority of the subjects (37 out of 48), the REE was measured by using indirect calorimetry (TrueOne2400, Parvo Medics, USA). The subjects were instructed to fast for at least 8 hours before the measurement and after arriving in the laboratory, they rested for at least 10 minutes before covering their heads with a facial mask while they were lying in a supine position. The facial mask was connected to the calorimeter, and the subjects were instructed to relax and stay awake during the measurement which lasted for 15 minutes. The respiratory data collected included the volume of oxygen consumed $\left(\mathrm{VO}_{2}\right)$, the volume of $\mathrm{CO}_{2}$ produced $\left(\mathrm{VCO}_{2}\right)$ and the respiratory quotient $(\mathrm{RQ})$, which were averaged over 1-minute interval for data analysis. The first 5 minutes of collected data were discarded, and the remaining 10 minutes was used to calculate REE, by using the Weir equation [20]. In the case of the remaining 11 subjects ( 8 men and 3 women) for whom we could not conduct indirect calorimetry due to technical problems with the machines, we used the predictive equations to estimate the REE. The most accurate equations were selected based on the results of indirect calorimetry from the measured group. In the case of men, the Huang equation [21] was used. In comparison to indirect calorimetry, this equation had a mean bias of $0.7 \%$ and an accuracy rate of $76 \%$. For women, the equation of Lazzer [22,23] was applied. Compared to the measured REE, the Lazzer equation had a mean bias $1.4 \%$ and the accuracy rate was $90 \%$.

\section{Dietary intake assessment}

The subjects' dietary intake was assessed by the 24-hour diet recall method. The dietary data were collected during the two weeks of DLW measurements. For every individual subject, three days data were collected, including two weeks days and one weekend day. The collected data were analyzed with the computer-aided nutritional analysis program (CAN pro) software (web version 5.0, Korean Nutrition Society, Seoul, Korea).

\section{Total energy expenditure (TEE) measurement}

TEE was measured over a period of 14 days, by using the DLW method. At the beginning, each subject provided a 20 $\mathrm{mL}$ urine sample, which was then followed by the ingestion of the DLW oral dose of $1.1 \mathrm{~g} / \mathrm{kg}$ of body weight. This dose was made of $1.03 \mathrm{~g}$ of $\mathrm{H}_{2}{ }^{18} \mathrm{O}$ (10\% enriched; Taiyo Nippon Sanso, Japan) and $0.07 \mathrm{~g}$ of $99.9 \%$ enriched ${ }^{2} \mathrm{H}_{2} \mathrm{O}$ (Sigma-Aldrich, USA) per kilogram of body weight. To ensure the accuracy of measurement, the used dose container was rinsed with $100 \mathrm{~mL}$ tap water which was then ingested by the subject. Post-dose urine samples were collected at day 1 (a day after dose ingestion), day 2, day 13 and day 14 . To reduce the risk of bias, the subjects were instructed to collect urine samples at a similar time of the day and the collection times were recorded. The collected samples were brought to the laboratory where they were kept at $-20^{\circ} \mathrm{C}$ before they were analyzed.

Urine analysis was done by using the isotope ratio mass spectrometry (IRMS), using a Sercon 20-20 spectrometer (Sercon Ltd., Crewe, UK).To calculate the $\mathrm{CO}_{2}$ production rate $\left(\mathrm{rCO}_{2}\right)$, the following formula was used [17]:

$$
\mathrm{rCO}_{2}(\mathrm{~mol} / \text { day })=0.4554 \times \operatorname{TBW}\left(1.007 \mathrm{k}_{\mathrm{o}}-1.041 \mathrm{k}_{\mathrm{h}}\right),
$$

Where TBW: total body water, $\mathrm{k}_{\mathrm{o}}$ : rate of ${ }^{18} \mathrm{O}$ elimination and $\mathrm{k}_{\mathrm{h}}$ : rate of ${ }^{2} \mathrm{H}$ elimination. TEE was calculated based on a multiple-point approach, using the modified Weir's formula as follows [24]:

$$
\text { TEE }(\mathrm{kcal} / \text { day })=22.4\left[3.9\left(\mathrm{rCO}_{2} / \mathrm{FQ}\right)+1.1 \quad \mathrm{rCO}_{2}\right] \text {. }
$$

The food quotient (FQ) was obtained by dietary intake records, by applying the equation of Black et al. [25]. The subjects' mean FQ was applied in the formula. Physical activity level (PAL) was determined as TEE/REE.

\section{$D R I$ equations for predicting EER}

To predict the EER, we applied the DRI equation published by the Institute of Medicine of the National Academies [16]. The physical activity coefficient (PA) which was applied in the equations, was deduced from every subject's PAL. Below are the assessed DRI equations for predicting the EER. 
EER for men aged 19 years and older: EER $(\mathrm{kcal} /$ day $)=662-[9.53 \times$ age $(\mathrm{yrs})]+\mathrm{PA} \times$

$[15.91 \times$ weight $(\mathrm{kg})+539.6 \times$ height $(\mathrm{m})]$,

Where PA is the physical activity coefficient:

$\mathrm{PA}=1.00$ if it is estimated that $1.0 \leq \mathrm{PAL}<1.4$ (sedentary)

$\mathrm{PA}=1.11$ if it is estimated that $1.4 \leq \mathrm{PAL}<1.6$ (low active) $\mathrm{PA}=1.25$ if it is estimated that $1.6 \leq \mathrm{PAL}<1.9$ (active)

$\mathrm{PA}=1.48$ if it is estimated that $1.9 \leq \mathrm{PAL}<2.5$ (very active)

EER for women aged 19 years and older:

EER $(\mathrm{kcal} /$ day $)=354-[6.91 \times$ age $(\mathrm{yrs})]+\mathrm{PA} \times$

[9.36 $\times$ weight $(\mathrm{kg})+726 \times$ height $(\mathrm{m})]$,

Where PA is the physical activity coefficient:

$\mathrm{PA}=1.00$ if it is estimated that $1.0 \leq \mathrm{PAL}<1.4$ (sedentary)

$\mathrm{PA}=1.12$ if it is estimated that $1.4 \leq \mathrm{PAL}<1.6$ (low active)

$\mathrm{PA}=1.27$ if it is estimated that $1.6 \leq \mathrm{PAL}<1.9$ (active)

$\mathrm{PA}=1.45$ if it is estimated that $1.9 \leq \mathrm{PAL}<2.5$ (very active)

\section{Development of new equations for predicting EER}

Based on the DLW results, the subjects' anthropometric variables were used to develop new predictive equations for EER. This was done by performing a nonlinear regression, using the iterative technique. The new equations were cross-validated and then their performance was compared with that of the DRI equations. Cross-validation was done by using the leave-oneout procedure [26], given the small size of our study sample. The technique consisted of removing one case from the sample and developing a regression equation based on the remaining cases. The obtained equation was then applied to the left-out case to predict the EER, and the error was computed by comparing the result with the measured TEE. This process was repeated on each case of the sample, with the regression equation obtained each time. The accuracy of our developed equations when applied on the corresponding left-out cases, represented the cross-validity of the regression equation based on all cases [26].

\section{Statistical analysis}

Data analyses were conducted with SPSS version 23 (IBM, USA). The results of descriptive statistics are presented as means \pm standard deviation (SD). To compare the results of men and women, independent t-test was used for normally distributed variables, and the Mann-Whitney $U$ test was used for the variables that were not normally distributed. The paired t-test

was used to compare the measured TEE and predicted EER

The accuracy of the EER predictive equations at the group level was evaluated by calculating the bias, which was expressed as the mean percentage error between the predicted EER and the measured TEE. At an individual level, an accurate prediction was defined as an EER prediction between $90 \%$ and $110 \%$ of the measured TEE, under-prediction as an EER prediction which was $<90 \%$ of the measured TEE, and over-prediction as an EER prediction which was $>110 \%$ of the measured TEE $[27,28]$. The accuracy rate was calculated as the percentage of subjects who had their EER predicted within \pm $10 \%$ of the measured TEE [29]. The root mean squared errors (RMSEs) were also used to assess the equations' accuracy. The RMSE was calculated as follows:

$$
\mathrm{RMSE}=\sqrt{\left[\sum\left(\mathrm{EER}_{\text {predicted }}-\mathrm{TEE}_{\text {measured }}\right)^{2} / \mathrm{N}\right]}
$$

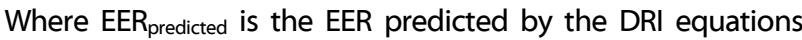
or by our developed equations, and $\mathrm{TEE}_{\text {measured }}$ is the TEE measured by the DLW method. The agreement between measured TEE and predicted EER was evaluated with the Bland-Altman method. Statistical significance was declared at $P<0.05$.

\section{RESULTS}

Characteristics of the subjects

The subjects' characteristics are presented in Table 1. The mean age was $72.2 \pm 3.9$ years for men and $70.0 \pm 3.3$ years for women. The weight, height and FFM were significantly higher in men than in women $(P<0.001)$. On the contrary, women

Table 1. Characteristics of the subjects

\begin{tabular}{|c|c|c|c|c|}
\hline & $\begin{array}{c}\text { Total } \\
(n=48)\end{array}$ & $\begin{array}{c}\text { Men } \\
(n=25)\end{array}$ & $\begin{array}{l}\text { Women } \\
(n=23)\end{array}$ & $P$-value ${ }^{2)}$ \\
\hline Age (yrs) & $71.1 \pm 3.8^{1)}$ & $72.2 \pm 3.9$ & $70.0 \pm 3.3$ & $0.05^{\mathrm{a})}$ \\
\hline Weight (kg) & $60.6 \pm 8.5$ & $64.8 \pm 6.6$ & $56.0 \pm 8.0$ & $<0.001^{\mathrm{a})}$ \\
\hline Height $(\mathrm{cm})$ & $159.1 \pm 7.8$ & $164.8 \pm 4.5$ & $153.0 \pm 5.9$ & $<0.001^{a)}$ \\
\hline BMI $\left(\mathrm{kg} / \mathrm{m}^{2}\right)$ & $23.9 \pm 2.4$ & $24.0 \pm 2.1$ & $23.9 \pm 2.7$ & $0.887^{\mathrm{a})}$ \\
\hline Fat mass $(\mathrm{kg})$ & $17.6 \pm 4.9$ & $16.3 \pm 4.4$ & $19.0 \pm 5.2$ & $0.053^{\mathrm{a})}$ \\
\hline Fat-free mass $(\mathrm{kg})$ & $43.0 \pm 7.0$ & $48.5 \pm 4.2$ & $37.0 \pm 3.5$ & $<0.001^{\mathrm{b})}$ \\
\hline$\%$ body fat & $29.0 \pm 6.7$ & $25.0 \pm 5.4$ & $33.4 \pm 4.9$ & $<0.001^{\text {a) }}$ \\
\hline
\end{tabular}

Table 2. Energy expenditure and physical activity level of the subjects

\begin{tabular}{|c|c|c|c|c|}
\hline & Total & Men & Women & $P$-value ${ }^{2)}$ \\
\hline REE (kcal/day) & $1,359.5 \pm 191.6^{1)}$ & $1,475.2 \pm 167.7$ & $1,233.7 \pm 126.4$ & $<0.00^{\mathrm{a})}$ \\
\hline REE/BW & $22.5 \pm 2.1$ & $22.9 \pm 2.4$ & $22.2 \pm 1.8$ & $0.304^{a)}$ \\
\hline TEE $_{\text {DLw }}$ (kcal/day) & $2,361.9 \pm 422.7$ & $2,673.3 \pm 297.4$ & $2,023.5 \pm 234.9$ & $<0.001^{\mathrm{a})}$ \\
\hline TEE/BW (kcal/kg/day) & $39.1 \pm 5.5$ & $41.5 \pm 4.9$ & $36.6 \pm 4.9$ & $0.001^{a)}$ \\
\hline PAL & $1.74 \pm 0.26$ & $1.83 \pm 0.28$ & $1.65 \pm 0.19$ & $0.062^{b)}$ \\
\hline $\mathrm{EER}_{\mathrm{DRI}}$ (kcal/day) & $2,200.0 \pm 406.9$ & $2,485.3 \pm 329.2$ & $1,889.3 \pm 204.1$ & $<0.001^{\mathrm{a})}$ \\
\hline $\mathrm{EER}_{\text {This study }}(\mathrm{kcal} /$ day) & $2,363.1 \pm 395.7$ & $2,671.4 \pm 251.7$ & $2,027.5 \pm 198.0$ & $<0.001^{\mathrm{a})}$ \\
\hline
\end{tabular}

1) Mean $\pm \mathrm{SD}$

2) $P$-value obtained by using ${ }^{\text {a) }}$ independent t-test or ${ }^{\text {b) }}$ Mann-Whitney $U$ test

REE, Resting energy expenditure; REE/BW, REE adjusted for body weight; TEEDLw, total energy expenditure measured by the DLW method; TEE/BW, total energy expenditure

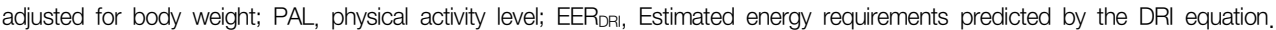


had higher body fat percentage than men $(P<0.001)$. The BMI did not differ significantly between the two groups.

Energy expenditure and physical activity level of the subjects

The mean REE was significantly higher in men than in women (Table 2), but not after adjusting for the subjects' body weight $(P>0.05)$. The TEE was also significantly higher in men than in women $(P<0.001)$, and this difference persisted even after adjusting for body weight. The PAL did not differ significantly between men and women $(P=0.062)$.

Developed equations for predicting EER in older adults We developed two equations (one for men and one for women), by using non-linear regression analysis with the iterative technique. These equations were then cross-validated for accuracy, by the leave-one-out technique [26]. The developed equations are presented below:

Men:

EER $(\mathrm{kcal} /$ day $)=2,377.07-[18.53 \times$ age $(\mathrm{yrs})]+\mathrm{PA} \times$ $[14.52 \times$ weight $(\mathrm{kg})+186.64 \times$ height $(\mathrm{m})]$

Women:

EER $(\mathrm{kcal} /$ day $)=334.15-[2.02 \times$ age $(\mathrm{yrs})]+\mathrm{PA} \times$

$[13.3 \times$ weight $(\mathrm{kg})+482.94 \times$ height $(\mathrm{m})]$

Where PA is the physical activity coefficient which depends

Table 3. Accuracy of the EER predictive equations based on bias, root-mean-squared prediction error (RMSE), and percentage of accurate predictions

\begin{tabular}{|c|c|c|c|c|c|c|c|c|}
\hline \multirow[t]{2}{*}{ Predictive equation } & TEE & Bias $^{1)}$ & $\begin{array}{c}\text { Maximum } \\
\text { negative error }^{2)}\end{array}$ & $\begin{array}{c}\text { Maximum } \\
\text { positive error }\end{array}$ & RMSE $^{4)}$ & $\begin{array}{c}\text { Accurate } \\
\text { predictions }^{5)}\end{array}$ & $\begin{array}{c}\text { Under } \\
\text { predictions }^{6)}\end{array}$ & $\begin{array}{c}\text { Over } \\
\text { predictions }^{7)}\end{array}$ \\
\hline & $\mathrm{kcal} /$ day & $\%$ & $\%$ & $\%$ & $\mathrm{kcal} /$ day & $\%$ & $\%$ & $\%$ \\
\hline \multicolumn{9}{|l|}{ Men } \\
\hline Measured TEE (TEE $\left.E_{\mathrm{DLW}}\right)^{8)}$ & $2,673.3$ & - & - & - & - & - & - & - \\
\hline EER $_{\text {DRI }}^{9)}$ & $2,479.6$ & -7.2 & -19.6 & 5.7 & 274.0 & 64 & 36 & 0 \\
\hline EER $_{\text {This study }}{ }^{10)}$ & $2,671.4$ & -0.1 & -15.4 & 19.7 & 191.9 & 84 & 8 & 8 \\
\hline \multicolumn{9}{|l|}{ Women } \\
\hline Measured TEE (TEE $\left.E_{D L w}\right)^{8)}$ & $2,023.5$ & - & - & - & - & - & - & - \\
\hline $\mathrm{EER}_{\mathrm{DRl}}^{9)}$ & $1,889.3$ & -6.6 & -18.8 & 4.7 & 189.7 & 74 & 26 & 0 \\
\hline $\mathrm{EER}_{\text {This study }}{ }^{10)}$ & $2,027.5$ & 0.2 & -15.2 & 14.6 & 155.0 & 83 & 4 & 13 \\
\hline \multicolumn{9}{|l|}{ All subjects } \\
\hline Measured TEE (TEE & $2,361.9$ & - & - & - & - & - & - & - \\
\hline $\mathrm{EER}_{\mathrm{DRI}}^{9)}$ & $2,200.0$ & -6.9 & -19.6 & 5.7 & 243.6 & 69 & 31 & 0 \\
\hline $\mathrm{EER}_{\text {This study }}{ }^{10)}$ & $2,363.1$ & 0.1 & -15.4 & 19.7 & 175.2 & 83 & 6 & 11 \\
\hline
\end{tabular}

${ }^{1)}$ Mean percentage error between predicted and measured TEE, or between EER and measured TEE.

2) The largest under-prediction that was found with this predictive equation as a percentage of the measured value

3) The largest over-prediction that was found with this predictive equation as a percentage of the measured value.

4) RMSE: root mean squared prediction error.

5) The percentage of subjects predicted by the DRI predictive equation within $10 \%$ of TEEDLw.

6) The percentage of subjects predicted by the DRI predictive equation $<10 \%$ below TEEDLw.

7) The percentage of subjects predicted by the DRI predictive equation $>10 \%$ above TEE

8) TEE

9) EER ${ }_{D R I}$ : Estimated energy requirements predicted by the DRI equation.

${ }^{10)}$ EERThis study: Estimated energy requirements predicted by our developed equation.
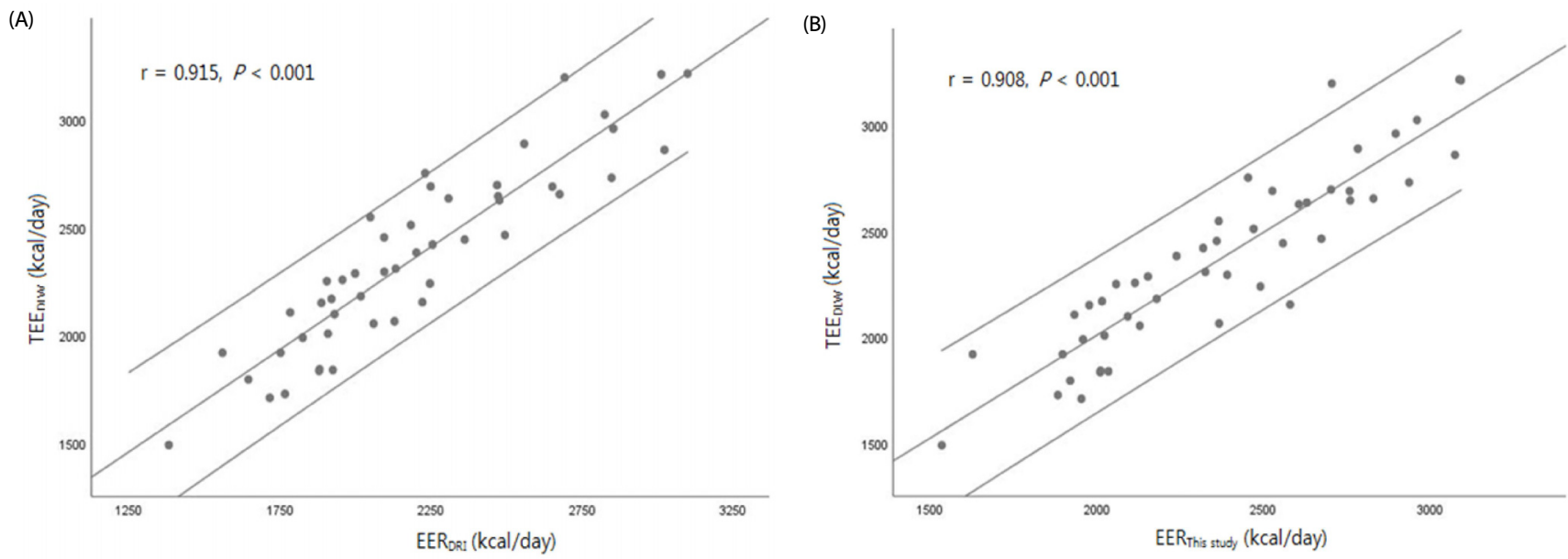

Fig. 1. Correlation between the EER predicted by the equations and the TEE measured by the DLW method. (A) DRI equations for EER prediction, (B) Our newly developed equations for EER prediction. TEEDLw, total energy expenditure measured by the doubly labeled water method; EERDRI, estimated energy requirement predicted by the DRI equation;

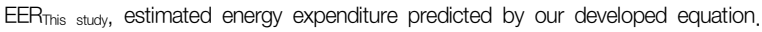



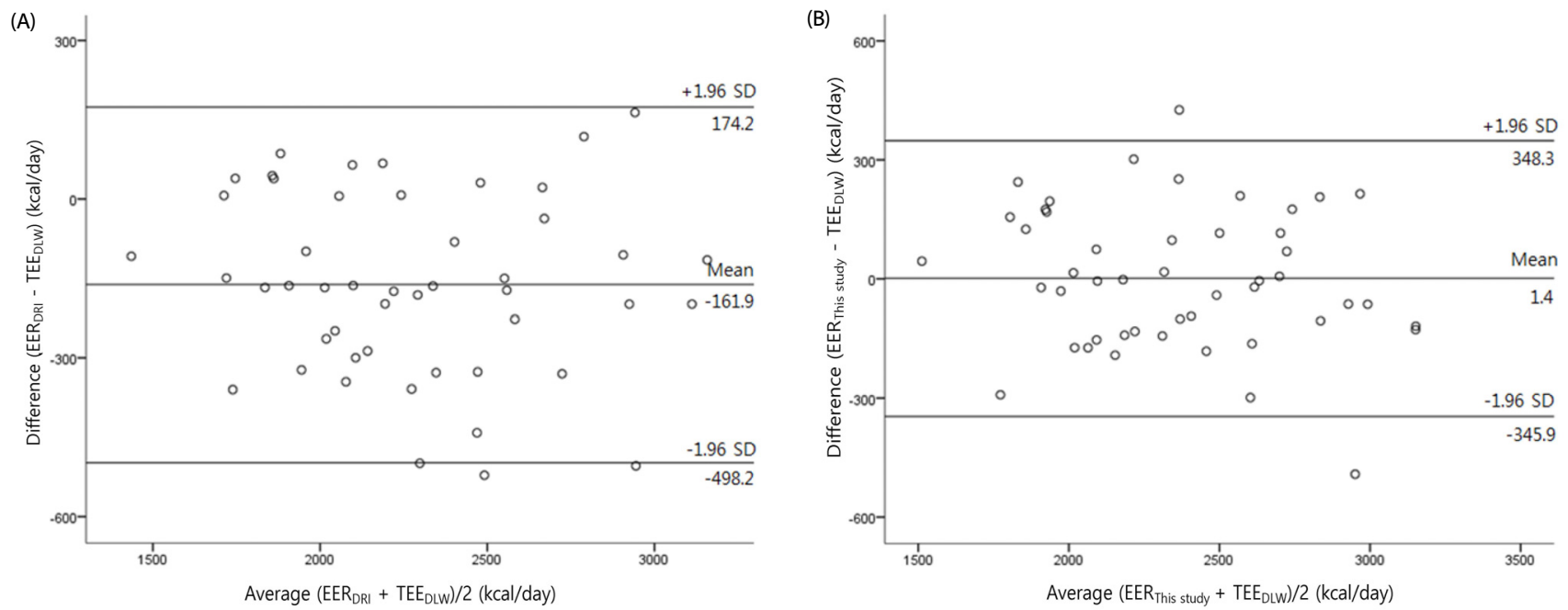

Fig. 2. Bland-Altman plots showing the agreement between the EER predicted by the equations and the TEE measured by the DLW method. (A) DRI equation for EER prediction, and (B) our newly developed equation for EER prediction. TEE predicted by the DRI equation; EERThis study, estimated energy expenditure predicted by our developed equation.

on the subject's PAL. We adopted the same values as those used in the DRI equations [16]:

\section{Accuracy of the EER prediction equations}

The DRI equations had a prediction bias of $-7.2 \%$ in men and $-6.6 \%$ in women, and the accuracy rate was $64 \%$ and $74 \%$, respectively (Table 3 ). Regarding our newly developed equations, the bias was $-0.1 \%$ in men and $0.2 \%$ in women, and the accuracy rate was $84 \%$ and $83 \%$, respectively. Among all subjects, the DRI equation had a bias of $-6.9 \%$ and an accuracy rate of $69 \%$, compared to $0.1 \%$ and $83 \%$ for the new equations, respectively. There was a very high correlation between measured TEE and predicted EER among all subjects (Fig. 1), both for the DRI equations (Pearson's $r=0.915, P<0.001$ ) and for our newly developed equations (Pearson's $r=0.908, P<$ 0.001). As presented in Fig. 2 , the Bland-Altman analysis resulted in limits of agreement of -498.2 to $174.2 \mathrm{kcal} /$ day for the DRI equations and -345.9 to $348.3 \mathrm{kcal} /$ day for our developed equations.

\section{DISCUSSION}

The TEE in older adults was measured by using the DLW method and the results were used as a reference to assess the validity of the DRIs for determining energy requirements in older adults. In addition, we developed two new predictive equations based on the subjects' TEE measured by the DLW method (TEE $E_{D L W}$ ) and their anthropometric variables, namely, age, body weight and height. The accuracies of both DRI and our newly developed equations were assessed by comparing the predicted EER with the measured TEE.

In men and women, the mean TEE $E_{D L w}$ was $2,673.3 \mathrm{kcal} /$ day and 2,023.5 kcal/day, and the REE was1,475.2 kcal/day and $1,233.7 \mathrm{kcal} /$ day, respectively. All these values were lower than those obtained by Tooze et al. in the OPEN study [30], where they used the DLW method to measure the TEE in 244 men and 206 women. In their study, in men and women, the mean $\mathrm{TEE}_{\mathrm{DLw}}$ was 2,899 $\mathrm{kcal} /$ day and 2,308 $\mathrm{kcal} /$ day and the REE was $1,716 \mathrm{kcal} /$ day and 1,328 kcal/day, respectively. These differences in energy expenditure could be related to the subjects' age, given that the REE which makes the largest contribution to the TEE [31], declines as an individual ages [24,31]. In our study, the mean age of the subjects was 72.2 years for men and 70.0 years for women. In the OPEN study, the mean subjects' age was 54.0 years for men and 52.8 years for women. Another factor that could explain the difference in energy expenditure findings between the two studies is that the subjects in the open study had a higher FFM than those in our study $(58.6 \mathrm{~kg}$ vs. $48.5 \mathrm{~kg}$ in men and $42.4 \mathrm{~kg}$ vs. $37.0 \mathrm{~kg}$ in women). An individual's amount of FFM has a positive impact on the REE [31,32].

Both the REE and TEEDLw were higher in men than in women, as already reported in previous studies [33-35]. The difference in REE could be explained by the subjects' weight and body composition, given that men had a higher body weight and FFM than women. After adjusting the REE for body weight, the gender difference disappeared. The difference in TEE $E_{D L w}$ seems to be related to the fact that men had higher body weight and FFM than women, given that their PAL was not significantly different.

The accuracy of the equations was assessed based on the mean bias, the percentage of subjects in whom the EER was accurately predicted, and the correlation between measured TEE and predicted EER. The DRI equations underestimated the EER by $7.2 \%$ in men and by $6.6 \%$ in women, and were accurate in $64 \%$ of the men and $74 \%$ of women. There was also a very high correlation between measured and predicted results, with a Pearson's $r$ of $0.915, P<0.001$.

Our study findings indicate that the DRI equations for predicting EER have an acceptable accuracy level when applied to older adults. These equations have been validated in previous studies, based on the results that were comparable to those 
obtained in the present study. The DRI equation was reported to be accurate in adults in a study by Kim et al. [34], which included seventy-one participants (35 men and 36 women) aged between 20 and 49 years. According to their study results for men and women, the mean bias was $-1.3 \%$ and $-4.9 \%$, the accuracy rate was77.1\% and $62.9 \%$ and the Pearson's $r$ was $0.783(P<0.001)$ and $0.810(P<0.001)$, respectively. Similarly, a study of Tooze et al. [30], which included 450 subjects (244 men and 206 women) aged 40-69 years, validated the use of the DRI equations for predicting EER. Their study found the DRI equations to have the mean bias of $5.9 \%$ for women and $7.5 \%$ for men. The rate of accurate predictions was $68 \%$ for men and $64 \%$ for women. They also found a strong correlation between the measured TEE and predicted EER, with a Pearson's $r$ of 0.93 .

In comparison to the DRI, our developed equations had a better performance with the mean bias between predicted EER and measured TEE of $-0.1 \%$ and $-0.2 \%$, and the accuracy rate of $84 \%$ and $83 \%$ in men and women, respectively. The new equations also had a smaller RMSE than the DRI equation (191.9 $\mathrm{kcal} /$ day vs. $274.0 \mathrm{kcal} /$ day in men and $155.0 \mathrm{kcal} /$ day vs. 189.7 $\mathrm{kcal} /$ day in women). However, these equations need to be independently validated by using a separate sample of older adults.

The present study was limited by the small sample size, mainly due to the high cost of the DLW method. Nevertheless, to the best of our knowledge, this is the first to assess the validity of the DRI for determining energy requirements in older adults, and then to develop and validate new equations for this population group. Another limitation is that approximately a quarter of the subjects (11 out of 48 ), we were not able to perform indirect calorimetry for the measurement of REE due to technical problems with the machines.

In conclusion, the DRI equations provided an acceptable EER prediction in older adults and these study results therefore support the use of these equations in this population group. Our developed equations had a better predictive accuracy than the DRI equations, but more studies need to be performed to assess the performance of these new equations when applied to an independent sample of older adults.

\section{CONFLICT OF INTEREST}

The authors declare no potential conflicts of interests.

\section{ORCID}

Didace Ndahimana: https://orcid.org/0000-0001-7070-3973

Na-Young Go: https://orcid.org/0000-0003-4803-7243

Kazuko Ishikawa-Takata: https://orcid.org/0000-0003-29952956

Jonghoon Park: https://orcid.org/0000-0002-5994-399X

Eun-Kyung Kim: https://orcid.org/0000-0003-1292-7586

\section{REFERENCES}

1. United Nations. World Population Ageing 2017: Highlights (ST/ESA/ SER.A/397). New York, NY: United Nations; 2017. p.1.

2. Arredondo A, Aviles R. Costs and epidemiological changes of chronic diseases: implications and challenges for health systems. PLoS One 2015;10:e0118611.

3. Scommegna P. Noncommunicable Diseases among Older Adults in Low- and Middle-Income Countries [Internet]. Washington, D.C.: Population Reference Bureau; 2012 [cited 2018 February 26]. Available from: http://www.prb.org/Publications/Reports/2012/non communicable-diseases-older-adults.aspx.

4. Kennedy BK, Berger SL, Brunet A, Campisi J, Cuervo AM, Epel ES, Franceschi C, Lithgow GJ, Morimoto Rl, Pessin JE, Rando TA, Richardson A, Schadt EE, Wyss-Coray T, Sierra F. Geroscience: linking aging to chronic disease. Cell 2014;159:709-13.

5. Sherman SE, D'Agostino RB, Cobb JL, Kannel WB. Does exercise reduce mortality rates in the elderly? Experience from the Framingham Heart Study. Am Heart J 1994;128:965-72.

6. Shahar DR, Yu B, Houston DK, Kritchevsky SB, Lee JS, Rubin SM, Sellmeyer DE, Tylavsky FA, Harris TB; Health, Aging and Body Composition Study. Dietary factors in relation to daily activity energy expenditure and mortality among older adults. J Nutr Health Aging 2009;13:414-20.

7. Qiu S, Cai X, Schumann U, Velders M, Sun Z, Steinacker JM. Impact of walking on glycemic control and other cardiovascular risk factors in type 2 diabetes: a meta-analysis. PLoS One 2014;9:e109767.

8. Schuler G, Adams V, Goto Y. Role of exercise in the prevention of cardiovascular disease: results, mechanisms, and new perspectives. Eur Heart J 2013;34:1790-9.

9. Friedenreich CM, Neilson HK, Farris MS, Courneya KS. Physical activity and cancer outcomes: a precision medicine approach. Clin Cancer Res 2016;22:4766-75.

10. Middleton LE, Manini TM, Simonsick EM, Harris TB, Barnes DE, Tylavsky F, Brach JS, Everhart JE, Yaffe K. Activity energy expenditure and incident cognitive impairment in older adults. Arch Intern Med 2011;171:1251-7.

11. Milanović Z, Pantelić S, Trajković N, Sporiš G, Kostić R, James N, Jorgic B. Age-related decrease in physical activity and functional fitness among elderly men and women. Clin Interv Aging 2013; 8:549-56.

12. Sun F, Norman IJ, While AE. Physical activity in older people: a systematic review. BMC Public Health 2013;13:449.

13. Normal human aging: the Baltimore Longitudinal Study of Aging. J Gerontol 1985;40:767.

14. Manini TM, Everhart JE, Anton SD, Schoeller DA, Cummings SR, Mackey DC, Delmonico MJ, Bauer DC, Simonsick EM, Colbert LH, Visser M, Tylavsky F, Newman AB, Harris TB. Activity energy expenditure and change in body composition in late life. Am J Clin Nutr 2009;90:1336-42.

15. Speakman JR, Westerterp KR. Associations between energy demands, physical activity, and body composition in adult humans between 18 and 96 y of age. Am J Clin Nutr 2010;92:826-34.

16. Institute of Medicine of the National Academies (US). Dietary Reference Intakes for Energy, Carbohydrate, Fiber, Fat, Fatty Acids, Cholesterol, Protein, and Amino Acids. Washington, D.C.: National Academies Press; 2002.

17. Park J, Kazuko IT, Kim E, Kim J, Yoon J. Estimating free-living human energy expenditure: Practical aspects of the doubly labeled water method and its applications. Nutr Res Pract 2014;8:241-8.

18. Roberts SB, Dallal GE. Energy requirements and aging. Public Health Nutr 2005;8:1028-36.

19. Roberts SB, Fuss P, Heyman MB, Young VR. Influence of age on 
energy requirements. Am J Clin Nutr 1995;62:1053S-1058S.

20. Weir JB. New methods for calculating metabolic rate with special reference to protein metabolism. J Physiol 1949;109:1-9.

21. Huang KC, Kormas N, Steinbeck K, Loughnan G, Caterson ID. Resting metabolic rate in severely obese diabetic and nondiabetic subjects. Obes Res 2004;12:840-5.

22. Lazzer S, Agosti F, Silvestri P, Derumeaux-Burel H, Sartorio A. Prediction of resting energy expenditure in severely obese Italian women. J Endocrinol Invest 2007;30:20-7.

23. Lazzer S, Agosti F, Resnik M, Marazzi N, Mornati D, Sartorio A. Prediction of resting energy expenditure in severely obese Italian males. J Endocrinol Invest 2007;30:754-61.

24. Ndahimana D, Kim EK. Measurement methods for physical activity and energy expenditure: a review. Clin Nutr Res 2017;6:68-80.

25. Black AE, Prentice AM, Coward WA. Use of food quotients to predict respiratory quotients for the doubly-labelled water method of measuring energy expenditure. Hum Nutr Clin Nutr 1986;40:381-91.

26. Drehmer DE, Morris GW. Cross-validation with small samples: An algorithm for computing Gollob's estimator. Educ Psychol Meas 1981;41:195-200.

27. Weijs PJ. Validity of predictive equations for resting energy expenditure in US and Dutch overweight and obese class I and II adults aged 18-65 y. Am J Clin Nutr 2008;88:959-70.

28. Frankenfield D, Roth-Yousey L, Compher C. Comparison of predictive equations for resting metabolic rate in healthy nonobese and obese adults: a systematic review. J Am Diet Assoc 2005;105:
775-89.

29. Marra M, Montagnese C, Sammarco R, Amato V, Della Valle E, Franzese A, Contaldo F, Pasanisi F. Accuracy of predictive equations for estimating resting energy expenditure in obese adolescents. J Pediatr 2015;166:1390-1396.e1.

30. Tooze JA, Schoeller DA, Subar AF, Kipnis V, Schatzkin A, Troiano RP. Total daily energy expenditure among middle-aged men and women: the OPEN Study. Am J Clin Nutr 2007;86:382-7.

31. Rolfes SR, Pinna K, Whitney EN. Understanding Normal and Clinical Nutrition. 9th ed. Belmont, CA: Wadsworth, Cengage Learning; 2012.

32. Nahikian-Nelms M, Sucher KP, Lacey K, Roth SL. Nutrition Therapy and Pathophysiology. 2nd ed. Belmont, CA: Wadsworth, Cengage Learning; 2011. p. 240.

33. Okubo H, Sasaki S, Rafamantanantsoa HH, Ishikawa-Takata $\mathrm{K}$, Okazaki H, Tabata I. Validation of self-reported energy intake by a self-administered diet history questionnaire using the doubly labeled water method in 140 Japanese adults. Eur J Clin Nutr 2008;62:1343-50.

34. Kim EK, Kim JH, Kim MH, Ndahimana D, Yean SE, Yoon JS, Kim $\mathrm{JH}$, Park J, Ishikawa-Takata K. Validation of dietary reference intake equations for estimating energy requirements in Korean adults by using the doubly labeled water method. Nutr Res Pract 2017;11: 300-6.

35. de la Torre $\mathrm{CL}$, Ramírez-Marrero FA, Martínez LR, Nevárez C. Predicting resting energy expenditure in healthy Puerto Rican adults. J Am Diet Assoc 2010;110:1523-6. 